\title{
COMPOSICIÓN, VARIACIÓN Y FUNCIONES DEL LEITMOTIV EN EL UNIVERSO INDIANA JONES
}

Teresa Piñeiro Otero ${ }^{1}$ : Universidade da Coruña. España.

teresa.pineiro@udc.es

\section{RESUMEN:}

La banda sonora de las películas asume un papel esencial en la experiencia del espectador. La música aporta a la imagen una serie de efectos, sensaciones y significados que dotan de una nueva dimensión a la narración audiovisual. El empleo de determinadas composiciones como los leitmotivs ha permitido establecer unos códigos audiovisivos con los espectadores, para una lectura enriquecida del relato cinematográfico. La integración de estos motivos recurrentes permite diversas posibilidades narrativas y expresivas por lo que su empleo ha sido bastante frecuente en la música fílmica. Autores como John Williams han hecho de los leitmotivs su sello personal, llegando a desarrollar un código propio para su composición y uso. En este sentido, el presente trabajo ha tenido por objeto efectuar un análisis del uso de los leitmotivs en la saga de Indiana Jones. Un análisis que se abordó desde una perspectiva narrativa del discurso musical.

PALABRAS CLAVE: Cine - Banda sonora - Música fílmica- Leitmotiv - Audiovisión - John Williams - Indiana Jones.

\section{LEITMOTIV COMPOSITION, VARIATION AND FUNCTIONS IN INDIANA JONES UNIVERSE}

\section{ABSTRACT:}

Films soundtrack assumes an essential rol in the viewer's experience. Music contributes to the image with a effects, feelings and meanings that endow of a new dimension to audiovisual storytelling. Determinate compositions employment like leitmotivs has allowed to establish some audiovisives codes with the viewers, for a enriched reading of cinematographic story. These recurrent themes integration

\footnotetext{
${ }^{1}$ Teresa Piñeiro Otero: Universidade da Coruña. España. teresa.pineiro@udc.es
} 
allows multiple narrative and expressive possibilities by what it employmen has been quite frequent in music film. Authors like John Williams have done of the leitmotivs his personal mark, with the develop a suitable code for its compositions and use. Present work aim was to effect an analyisis of leitmotiv use in Indiana Jones saga. An analysis from a narrative perspective of the musical speech.

KEY WORDS: Film - Soundtrack - Film music - Leitmotiv - Audiovision - John Williams - Indiana Jones.

\section{INTRODUCCIÓN}

La música desarrolla un papel clave en nuestra experiencia audiovisual. Aunque en un relato cinematográfico la imagen constituye el foco consciente de la atención, es la banda sonora la encargada de aportar una serie de efectos, sensaciones y significados que dotan de una nueva dimensión a la narración audiovisual.

Como señala Elmer Bernstein las películas conspiran con la imaginación para que el espectador se evada de su realidad y se sumerja en un viaje espontáneo por su inconsciente. En este sentido "La música constituye, probablemente, uno de los mejores aislante de la realidad. De todas las artes la música es la que más directamente apela a las emociones" (Bernstein citado en Burt, 1994: p.10)

La música puede condicionar el alcance de una película; dotar de una estructura narrativa al relato, comunicar su atmósfera, tono e incluso género; subrayar el tipo y tamaño del espacio; destacar la energía de la acción; presentar la vida interior, los pensamientos y sentimientos de un personaje... en definitiva, puede aportar la perspectiva del director respecto al tema tratado. En este sentido Gobman (1987) se refirió a la "communtación" como la capacidad de la música para describir al máximo la esencia de un film.

Desde el momento en que la música irrumpe en pantalla incideen la creación y definición de la diégesis fílmica, así como en la construcción del discurso audiovisual desde perspectivas tan diversas como formal, narrativa, dramatúrgica, estética o psicológica (Torrelló y Durán, 2014: p. 111).

La banda sonora, por tanto, no se sitúa en el mismo plano que la imagen sino que se yuxtapone a ésta logrando su significado por la relación que establece ésta con en el espacio fílmico (Aumont y Marie, 1990).

Este fenómeno para el que Chion acuñó el término "audiovisión" (1990) constituye una compleja organizacion perceptiva -única e indivisible- que permite señalar determinadas estructuras de producción de sentido (Costantini, 2002). Siguiendo a Bernard Herrmann "la música constituye un vínculo comunicativo entre la pantalla y el público, alcanzando y desarrollando todo en una única experiencia" (Herrmann citado en Burt, 1994: p. 11). 
Pese a la relevancia que adquiere la banda sonora en la narración audiovisual su empleo apenas ha sido estudiado. Aunque implícito en las teorías fílmicas, el rol de la música e el cine no ha tenido un abordaje riguroso hasta la década de los 70 con la irrupción de las teorías contemporáneas del audiovisual. Hoy la investigación académica se decanta por efectuar aproximaciones a determinados aspectos de la banda sonora contemporánea a partir del análisis de películas concretas. Una tipología de análisis como el que se propone para la tetralogía de Indiana Jones: En busca del arca perdida (Raiders of the Lost Ark, 1981), Indiana Jones y el templo maldito (Temple of Doom, 1984), Indiana Jones y la última cruzada (1989, The Last Crusade) e Indiana Jones y el reino de la calavera de cristal (The kingdom of the Crystal Skull, 2008).

\subsection{La música en Indiana Jones}

Dentro de la filmografía de Steven Spielberg la saga de Indiana Jones se incluye en la ficción basada en antiguas series de televisión, siguiendo la categorización propuesta por Peña (2009). George Lucas quería desarrollar una saga de aventuras que mantuviese la esencia de los seriales que se popularizaron durante los años 30 y 40. Este proyecto se materializó a inicios de la década de los 80 con En busca del arca perdida (1981), dirigida por Spielberg, en la que se presenta a Henry Walton Jones Jr., más conocido como Indiana Jones.

Desde esta primera entrega se percibe el tributo de las películas de Indiana Jones al ritmo y estilo de los antiguos seriales de aventuras, también con la creación de un héroe y un universo narrativo que remiten a diversos referentes de la cultura popular de la primera mitad del siglo XX. Entre ellos al propio James Bond, cuyo estilo imita Jones en su visita al club de El templo maldito.

Harrison Ford personifica del héroe de los cómics y las novelillas de aventuras de la década de los 30 . Aunque es un mercenario cuenta con un aura de heroicidad que se sustenta en la pasión con la que Jones desarrolla cada encargo. Como señala George Lucas (citado en Champin, 1992, p. 79 y ss.) más que por el dinero Indiana Jones se mueve por la emoción de la búsqueda, lo que le hace amar la arqueología y con ésta su papel en el descubrimiento de la verdad sobre las antiguas civilizaciones y la historia.

Inspirado en los grandes mitos, Indiana Jones presenta características como fuerza, rapidez e ingenio, y un cierto sex-appeal -como acreditan sus alumnas- que permite introducir una trama romántica en las películas. Como muchos héroes de aventuras, Jones presenta una dupla personalidad como profesor y arqueólogo; una profesión que le llevará a abandonar su cátedra en la Universidad Barnett para buscar objetos clave en la historia de la humanidad. Todas estas características convierte a Jones en la encarnación del arquetipo de héroe capaz de hacer frente a cualquier adversidad (Aschieri, 1998: p. 252).

En su caracterización, Jones guarda importantes similitudes con Charlton Helston en El secreto de los Incas (The Secret of the Incas, 1954). Si bien, como señala López 
Olano (2001, P. 77), su célebre sombrero (una fedora marrón) se lo debe al personaje interpretado por Humphrey Bogart en el El tesoro de Sierra Madre (The treasure of the Sierra madre, 1948).

La ambientación sonora y musical de la saga de Indiana Jones también se ha inspirado en la banda sonora -en su sentido más amplio- de los seriales de aventuras que plagaron la imaginería popular en las décadas de los 30 y 40 . Dado su carácter de película de acción la música intenta generar cierta expectación en la audiencia, suscitando excitación a través de orquestaciones vívidas, determinadas progresiones compositivas y vitalidad rítmica (Bezuidenhout, 2009).

Como señala Boam (citado en Aschieri, 1998: p. 267) "George Lucas y Steven Spielberg han creado un género muy nuevo a partir de uno muy viejo".

En efecto, la saga de Indiana Jones supone una renovación del género, a la que ha contribuido importantemente la partitura de Williams, compositor con el que Spielberg ha formado uno de los tándem creativos más longevo y fructífero de Hollywood (con más de una veintena de películas y una producción televisiva desde 1974). Esta relación ha llevado a llevado a considerar algunas de las características compositivas de Williams dentro del estilema de autor de Spielberg (Caldevilla, 2005).

La banda sonora de la saga constituye una de los scores más populares y enérgicos de Williams, especialmente en lo que respecta al tema de Indiana Jones (Aschieri, 1998: p. 252). Si bien los principales atributos del célebre arqueólogo son su fedora marrón y su látigo, resulta impensable hablar de Indiana Jones sin recordar su tema musical.

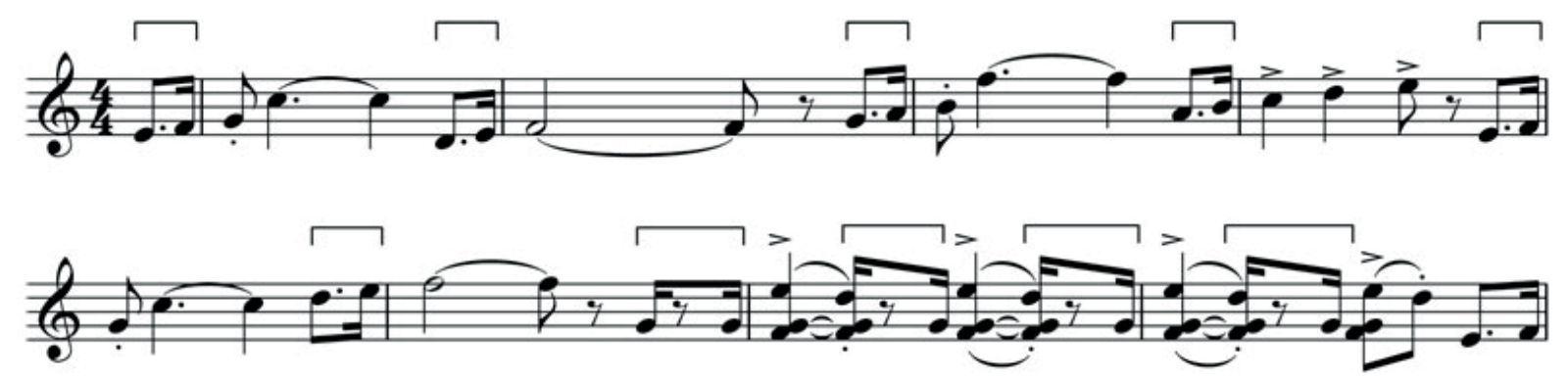

Imagen 1: Leitmotiv de Indiana Jones.

Más allá del tema principal, la música en la tetralogía resulta esencial para la experiencia final del espectador.

Como relato serial, fragmentado en cuatro películas, la ambientación musical juega un papel relevante en la coherencia y continuidad de la serie. Siguiendo a George Lucas cuando se plantea la continuación de una película existe una disciplina establecida que funciona a modo de sonata o de "haiku". Si bien se puede apelar a una cierta liberta creativa, una vez que se ha desarrollado un estilo y género se debe ser fiel a éste (Citado en Champlin, 1992: p. 153) 
Además de su empleo como elemento de continuidad, la música en la saga de Indiana Jones se ha utilizado también con carácter descriptivo-narrativo. La predilección de Williams por el leitmotiv ha dotado de una nueva dimensión narrativa a personajes e, incluso, objetos relevantes cuya presencia se hace patente siempre que suena el tema que los acompaña.

El score original de la película también incluye algunas composiciones que (tipo de escala, tonalidad, armonía, orquestación, etc.) remiten al lugar y momento histórico donde se desarrolla la acción. Un ejemplo de ello es el tema "The temple of Doom", perteneciente a la banda sonora de Indiana Jones y el templo maldito (1984) cuya instrumentación, sonoridad e incluso letra de la canción -escrita en sánscritopretenden crear una atmósfera convincente de tiempo y lugar. El efecto que Aaron Coplan denomina "color local" de la música.

Desde la perspectiva de la acción, Frith (1988) ha destacado la utilización del rimo armónico para respaldar la trama narrativa. Cada vez que esta trama se resuelve, la música lo refleja acompañando esta acción de un modo consonante. Del mismo modo el fondo musical de los personajes es más disonante cuando se plantea el conflicto, adquiriendo una forma más consonante cunado se acerca a su fin (Frith, 1988).

Para las gestas de Jones Williams capta cada matiz visual de escena integrándolo en la partitura como si se tratase de un ballet. Este es el caso de "Desert Chase", una de las secciones de la película de En busca del arca perdida (1981) cuya concepción es definida así por el compositor:

Lo visualicé como una especie de número musical que tiene un comienzo, un desarrollo y un final, y calculando la serie de tiempos y de tiempos variables. Traté de diseñarlo casi de la misma manera que un ballet, que puede contribuir con cierto aspecto de entretención y aventura en este personaje de Harrison Ford. La música puede sonar seria, pero no es seria realmente, se ha concebido de una manera más teatral y espero que siempre tenga el aspecto de entretención o igual campo sobre ésta (John Williams citado en Aschieri, 1998: p. 253).

Tal como señala Caldevilla (2000, p. 913 y ss) se pueden destacar tres tipologías de música descriptiva-narrativa en la saga de Spielberg, atendiendo al momento de su inserción: antecedente, concomitante y consecuente.

- La música antecedente se inserta antes de la acción y aporta información sobre su desenlace, como sucede en la escena de escape del Pozo de almas de En busca del arca perdida (1981).

- La música concomitante acompaña a la imagen durante la aparición de personajes y desarrollo de la acción, siendo la más común en toda la saga.

- Finalmente, la música consecuente es aquella que va por detrás de la acción, completando su significado. No es muy habitual en la saga y su empleo se limita a aquellas secuencias cuya resolución no parece muy clara, 
manteniendo la incertidumbre. Un ejemplo de ello se encuentra en la huida de la mina en Indiana Jones y el Templo Maldito.

Siguiendo a Caldevilla, la música concominante la que revela el sello personal del compositor en tanto que vehicula la mayoría de las apariciones de los leitmotivs así como aquellas composiciones que ayudan a los espectadores a situarse en un tiempo-espacio concreto. "El binomio Spielberg-Williams se manifiesta en este apartado con fuerza propia ya que los otros dos hacen referencia al empleo de los elementos conformantes, no a su naturaleza". Caldevilla (2000, p. 914).

Otra característica de la música en la tetralogía y, en general, en toda la obra de Spielberg es su carácter extradiegético. Pese a que se incorporan algunos temas diegéticos como el popular Hound Dog de Elvis Presley que reproduce la autorradio en El reino de la calavera de cristal, el número musical de una vedette con el que se inicia El templo maldito, los tambores y cánticos que se escuchan en las entrañas del palacio de Pankot, o la música que suena en la cafetería donde Mutt habla con Indiana en La calavera de Cristal, la mayor parte de la música pertenece a los "fosos imaginarios" (Jullier, 2007; Chion, 1993).

El score de Williams, creado específicamente para estas películas, ayuda a captar de forma magistral la esencia de la saga, su tono emocional, al tiempo que captura y articula la experiencia visual de los espectadores. Como destaca Scheurer (1997), en sus bandas sonoras Williams apuesta por el desarrollo artístico, buscando constantemente la metáfora audiovisual que permitirá a los espectadores ampliar la experiencia más allá de sus expectativas. Una apuesta que se hará patente a lo largo de las cuatro entregas de Indiana Jones.

\subsection{El leitmotiv. El elemento estrella en la obra de Williams.}

En las bandas sonoras de Williams se observa su formación clásica, tanto en sus orquestaciones -que han llevado a la denominación de su estilo como neosinfonismocomo en el empleo de elementos característicos de diversos compositores. En sus fanfarrias y marchas -algunas de ellas utilizadas en Indiana Jones- se puede observar la influencia de autores como Gustav Malher o Johann Strauss (Lincoln, 2010).

No obstante, ha sido Richard Wagner el compositor que más veces se ha relacionado con el estilo Williams. Una relación que se ha basado en el paralelismo existente entre el Anillo de los Nibelungos, la tetralogía wagneriana, y la música de Williams en Star Wars. Siguiendo a Reginfo (2010, p. 96), algunas de las características comunes a las obras de ambos autores son el formato grande orquestal, el empleo del cromatismo, la inclusión frecuente de ostinatos o glissandos y, sobre todo, el uso del leitmotiv.

Unos leitmotivs que Wagner definió como momentos musicales y temas básicos. No obstante, pese a su aparente simplicidad la composición de estos motivos musicales está cuidadosamente tratada para causar una serie de sensaciones y asociaciones en el oyente (Costantini, 2001) 
Siguiendo a Costantini (2001) un leitmotiv es un tema específico o motivo que representa a un personaje, un objeto o una acción recurrente. Este tema suele emplearse fundamentalmente con una función descriptiva, aunque se pueden señalar otros usos como el sustitutivo -que supone la máxima identificación del motivo con el actante- o el indicativo -que le señala al espectador algún aspecto clave para la comprensión del relato [por ejemplo el leitmotiv de M. El vampiro de Düsseldorf (1931) identifica al asesino].

A pesar de las múltiples posibilidades que presenta el leitmotiv para la decodificación de la imagen su uso ha sido denostado por Adorno y Eisler (1981) al considerarlo un artificio simbólico, que inhabilita la apariencia de realidad de un film y reduce su contenido emocional a un proceso mecánico.

Williams ha incorporado magistralmente el leitmotiv wagneriano a sus bandas sonoras, convirtiéndolo en uno de los elementos definitorios de su sello personal. Star Wars, Superman, la saga de Indiana Jones, ET son solo algunas de las películas que son recordadas por la utilización de este tipo de composiciones. Dentro de la obra de Williams probablemente el leitmotiv más famoso sea el de Tiburón (Jaws, 1975). Un tema muy básico, compuesto por dos notas que se repiten incrementando su intensidad y tempo.

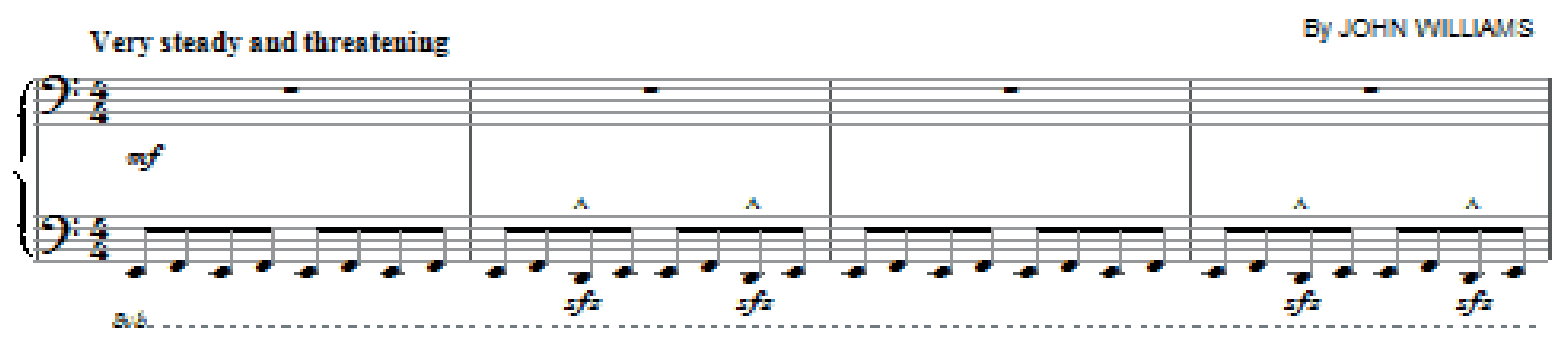

Imagen 2: Leitmotiv de Tiburón.

En la obra de Williams "cada personaje-clave o cada idea-fuerza del relato están dotados de un tema que los caracteriza y constituyen su ángel guardián musical" (Chión, 1993)

Su predilección por los leitmotivs han llevado a Williams a desarrollar su propio código compositivo. Como señala Costantini (2001) el compositor emplea escalas diatónicas para representar al héroe (Indiana Jones, Superman y Star Wars), mientras que los motivos de objetos o situaciones de peligro utilizan escalas cromáticas (Tiburón). Utiliza timbres brillantes para caracterizar elementos positivos e instrumentos oscuros, en tesituras extremas, para representar lo negativo.

El mismo tema sirve a Williams para apoyar las más diversas acciones o estados de ánimos de su personajes a través de la variación del tono, intensidad, orquestación o tempo. De este modo el leitmotiv se adecúa a cada situación para describirla aunque sin apartarse de la curva melódica que lo identifica (Caldevilla, 2000). 


\section{OBJETIVOS}

Partiendo del uso del leimotiv como elemento característico del estilo de Williams se ha establecido como objetivo principal de este trabajo estudiar el empleo de esta tipología de temas o motivos musicales, desde una perspectiva narrativa, en la tetralogía de Indiana Jones.

Este objetivo principal se ha desagregado en dos objetivos específicos:

- Concretar la presencia y utilización de temas o motivos musicales asociados a personajes y objetos en la saga de Indiana Jones.

- Analizar el empleo de The Raiders March como leitmotiv del protagonista.

\section{METODOLOGÍA}

Para abordar el estudio de los leitmotivs en Indiana Jones se ha efectuado un análisis del discurso musical y su relación con la imagen en la saga, debido a que juntos forman un continuum perceptivo que Chion denominó audiovisión.

Este análisis constituye una aproximación al uso de los leitmotivs en las cuatro películas de la tretralogía, así como a su funcionalidad, significación e implicaciones. Una aproximación que presenta una perspectiva innovadora del estudio de la música en el cine en tanto que trasciende el análisis semiótico para centrarse en la forma musical y en su reiteración.

Se parte de la consideración de un leitmotiv como toda aquella pieza de música -ya sea una melodía, fragmento musical, progresión armónica, etc.- que cuenta con más de una inserción durante el transcurso de la película siempre asociado a una acción o actante concreto (sin esta asociación sería una Idée fixe).

Esta tipología de temas se integran en el discurso musical e interactúan con la imagen -como señalan Gertrudix Barrio y García García (2013)- vectorializando su lectura, por lo que el estudio de los leitmotivs implica también una aproximación narrativa.

Con la finalidad de efectuar un análisis sistemático del discurso audiovisual se han desarrollado diversos tipos de visionados en cada una de las películas de la saga. En primer lugar se ha efectuado una lectura convencional de los filmes. Posteriormente se fragmentó la película en secuencias para reiterar el visionado de los fragmentos que vehiculasen algún tipo de leitmotiv. Finalmente, se repitió dicho visionado siguiendo el proceso que Chion (1993) denomina "método de ocultadores", esto es, se desarrolló una doble lectura de cada fragmento ocultando la imagen para efectuar una "escucha acusmática" (Schaeffer, 1966) y eliminado el sonido para un visionado mudo.

Durante el proceso de visionado se utilizó una ficha de análisis basada en el esquema de vínculos y funciones de los leitmotivs desarrollado por Constantini (2001). 


\section{DISCUSSION}

\subsection{LOS LEITMOTIVS EN INDIANA JONES. VINCULACIONES Y FUNCIONES.}

\subsubsection{El leimotiv de Indiana Jones}

Desde su primera aparición en el minuto 11 de En busca del arca perdida (1981), cuando Indiana Jones logra escapar de la tribu que lo persigue por sustraer un objeto sagrado, el tema Raiders March se convierte en la marca sonora de Indiana Jones (tanto de la saga como al personaje). A partir de esta inserción se puede señañar la presencia de este leitmotiv en más de sesenta secuencias de la saga.

Este tema representa al personaje en tanto que -si tomamos como referencia las tablas de Beltrán Moner (1991)- su timbre brillante, tesitura media-aguda, armonía mayor, ritmo regular, orquestación llena y fraseo melódico remiten a determinados atributos de Indiana Jones como su valentía, pasión, honor, etc.

Asimismo, el inicio del leitmotiv de Indiana Jones incluye un intervalo de cuarta frente a los intervalos de quinta que están presente en otros temas de héroes compuestos por Williams como el de Superman el de Star Wars. En este sentido se puede considerar que la música identifica a un héroe, pero más humano.

El empleo de este leitmotiv como elemento identificador del personaje se refrenda en el La última cruzada, donde un joven Indiana Jones vive su primera aventura para despojar a unos mercenarios de una reliquia -la Cruz de Coronado- que él considera que debería pertenecer al erario público. Aunque en esta aventura se presenta un tema específico, que actuará de leitmotiv para el joven Indy, en ocasiones este tema deja paso a Raiders March para subrayar acciones valerosas que ya esbozan el carácter de un adulto Indiana Jones: el robo de la cruz, su destreza en el tren, la huida hacia casa.

Este leitmotiv también se vincula a sus otros atributos como el látigo -que ayuda al joven Indy a zafarse del león (La última cruzada)- y al sombrero -en el momento que el jefe de los mercenarios le regala su fedora negra (La última cruzada), cuando Indiana sale del maletero del coche en la base tomada por los rusos, o tras la boda acompañando a un sombrero que vuela a los pies de Mutt (El reino de la calavera de cristal).

Más allá de identificar y caracterizar al personaje, las variaciones de este tema que se pueden escuchar a lo largo de las cuatro películas de la saga, permiten efectuar una aproximación más concreta a los sentimientos y a la situación del héroe en cada momento. El tema de Indiana Jones puede aparecer esbozado dentro de la música incidental e incluso entrar en conflicto con ésta (por ejemplo la secuencia de la biblioteca en La última cruzada), variar sus instrumentos y sonoridad para adaptarse al color local de música (por ejemplo en el vuelo hacia El Cairo en En busca del arca perdida), cambiar el tempo para que resulte más viva (caída de la liana en En busca 
del arca perdida) o más lenta (tras salir del maletero del coche se recompone en El reino de la calavera de cristal), cambiar su tesitura (cuando Henry Jones salva a su hijo de caer por una grieta en el suelo, en La última cruzada, suena grave y lento) o tonalidad (el veneno lleva a la aparición de otro Indiana, en El templo maldito, y lo refleja su música en modo menor).

Este uso se asocia con la función descriptiva señalada por Costantini (2002) para los leitmotivs. De hecho esta función, la de describir la situación o las acciones del héroe constituye el empleo más habitual del leitmotiv de Indiana Jones en la saga. Cuando Indiana Jones efectúa una hazaña épica, logra escaparse de sus persecutores, emprende [o reemprende ] una nueva aventura e incluso cuando es consciente que le ha fallado su plan suele escucharse el famoso motivo. Es el tema de Indiana, el que lo identifica, y por eso también le acompaña en determinadas acciones en entornos más cotidianos, como la de escaparse por la ventana de su despacho para huir de una caterva de estudiantes ( La última cruzada) o la de aconsejar -con cierta sorna- a un alumno que deje la biblioteca y se dedique más al trabajo de campo (EI reino de la calavera de cristal).

\begin{tabular}{|c|c|c|}
\hline PEĹCULA & ACá́n & PUnCión \\
\hline Arca perdida & Indiana Jones escapa con una liana y cae al agua. El leitmotiv se repetirá también en su viaje en avioneta. & Descriptiva \\
\hline Arca perdida & $\begin{array}{l}\text { Tras informar a los hombres del Gobierno sobre el arca, Marcus lo visita para indicarle que se prepare par } \\
\text { su búsqueda. }\end{array}$ & Indicativa \\
\hline Arca perdida & Indiana monta en una a vioneta. Viaje hacia Nepal & Descriptiva \\
\hline Arca perdida & Viaje hacia B Cairo, ya con Marion, deriva en su leitmotiv. & Descriptiva \\
\hline Arca perdida & $\begin{array}{l}\text { Situa do el lugar exacto del Arca, Indiana curza el campamento de las explora ciones con un atuendo } \\
\text { tradicional. }\end{array}$ & Descriptiva \\
\hline Arca perdida & Indiana sube en la estatua para conseguir derribar el muro. Presentan unas nctas del tema. & Descriptiva \\
\hline Arca perdida & Indiana ataca la avioneta Nazi Se esbczan notas de su leitmctiv. & Descriptva \\
\hline Arca perdida & $\begin{array}{l}\text { Acomete el rescate de Marion, que está encerrada en un avión. Se escuchan unas notas cada vez que } \\
\text { avarza en la situación hasta que logran escapar. }\end{array}$ & Descriptiva \\
\hline Arca perdida & $\begin{array}{l}\text { Indiana persigue el camión que lleva el arca. Suena con gran intensidad. Se escucha en diversos } \\
\text { momentos durante la persecución y toma de éste }\end{array}$ & $\begin{array}{l}\text { Descriptiva- } \\
\text { Indicativa }\end{array}$ \\
\hline Arca perdida & Indiana hace equilibrios sobre la "cubierta" del submarino. Tema con gran intensidad. & Descriptiva \\
\hline Arca perdida & $\begin{array}{l}\text { Entra por sorpresa en el submarino. Intenta difrazarse de nazi pero no le sirve el uniforme (leitmotiv } \\
\text { subraya comicidad de la situación) }\end{array}$ & Descriptiva \\
\hline Arca perdida & Vuel ven a tierra, como miembro del ejército Nazi. & Descriptiva \\
\hline
\end{tabular}

Tabla 1: Secuencia de inserción y funciones del leitmotiv de Indiana Jones en 'El busca del Arca perdida'. Fuente: Elaboración propia. 


\begin{tabular}{|c|c|c|}
\hline PELÍCULA & ACCIÓN & FUNCIÓN \\
\hline Templo maldito & $\begin{array}{l}\text { Con la llegada al aeródromo se esboza por primera vez. Cuando está a punto de escaparse en el avión y } \\
\text { se burla sus persecutores suena más claro. }\end{array}$ & $\begin{array}{l}\text { Descriptiva- } \\
\text { Indicativa }\end{array}$ \\
\hline Templo maldito & Saltan del avión sobre una balsa hinchable. & Descriptiva \\
\hline Templo maldito & Pelea con asaltante nocturno, en cuanto lo domina se esboza su tema. & $\begin{array}{l}\text { Descriptiva- } \\
\text { Indicativa }\end{array}$ \\
\hline Templo maldito & La cámara comienza a cerrarse otra vez. Indiana salva a Willie antes de morir aplasados. & Descriptiva \\
\hline Templo maldito & Tras contarle el niño que la sangre te sumerge en una pesadilla, se vuelve a esbozar el tema de Indiana. & Indicativa \\
\hline Templo maldito & $\begin{array}{l}\text { Indiana Jones va a sacrificar a Tapón. Una treta con la que Indiana Jones tomará la iniciativa para atacar a } \\
\text { los Thuggee. }\end{array}$ & Descriptiva \\
\hline Templo maldito & Durante la pelea se esbozará en diversas ocasiones su tema. & Descriptiva- \\
\hline Templo maldito & Tras salvar a Willie, Indiana recupera sus bolsa, las piedras y sus atributos. Suena melancólica. & Descriptiva \\
\hline Templo maldito & Tapón se encuentra enganchado entre dos vagonetas. Se esbozar el tema. & Descriptiva \\
\hline Templo maldito & $\begin{array}{l}\text { Escapando de la gruta del palacio, corre por el bosque libre y suena su tema. De repente para, porque se } \\
\text { ecuentra con dos espadachines del Maharahá. Su tema volverá a resonar cuando parece que vence, y } \\
\text { después cuando escapa por el puente. }\end{array}$ & $\begin{array}{l}\text { Descriptiva- } \\
\text { Indicativa }\end{array}$ \\
\hline Templo maldito & De vuelta en el pueblo, en una situación tranquila recibe el agradecimiento de la gente. & Descriptiva \\
\hline
\end{tabular}

Tabla 2: Secuencia de inserción y funciones del leitmotiv de Indiana Jones en 'El templo Maldito' Fuente: Elaboración propia.

Otros momentos en los que este leitmotiv se utiliza con una función descriptiva son las secuencias de acción, cuando Indiana tiene que enfrentarse a su enemigo, recuperar la reliquia robada, liberar a sus colaboradores o escapar. En estas secuencias el tema de Indiana Jones se esboza en diversas ocasiones, integrándose en un pasaje musical más disonante (si la confrontación continúa) o caminando hacia un tema más consonante si Indiana Jones va a lograr su cometido. Es el caso del asalto al camión nazi en el que portan el arca de la alianza (En busca del arca perdida), la liberación de los niños en el templo de la hermandad Thuggee ( $E$ I templo maldito), la confrontación con Donovan y sus aliados en las inmediaciones del templo del grial (La última cruzada) o cuando lo asaltan a él y a Mutt al salir de la cafetería ( $E$ r reino de la calavera de crista).

En estos casos se puede hablar también de una función indicativa de este leitmotiv dado que no sólo describen la situación del héroe en la confrontación, sino que indica cuando Indiana Jones logra imponerse a sus rivales 0 -en el caso de que tenga la ayuda de sus colaboradores- quién golpea en cada momento.

También se puede señalar un uso indicativo de este leitmotiv en la última película de la saga cuando, después de que los rusos lo sacaran a la fuerza del maletero de un coche, logra recomponerse y ponerse su sombrero. El tema destaca la vuelta de Indiana Jones. 


\begin{tabular}{|c|c|c|}
\hline PELÍCULA & ACCIÓN & FUNCIÓN \\
\hline Última Cruzada & Indiana Jones se escapa a galope. & $\begin{array}{c}\text { Descriptiva- } \\
\text { Indicativa }\end{array}$ \\
\hline Última Cruzada & $\begin{array}{l}\text { Cae en el vagón del león. Cuando siente que no tiene escapatoria ve un látigo e instantáneamente se } \\
\text { esboza el tema principal, lento y solemne. }\end{array}$ & $\begin{array}{c}\text { Descriptiva- } \\
\text { Indicativa }\end{array}$ \\
\hline Última Cruzada & Tras escaparse de los ladrones llega a su casa, deriva del leitmotiv de Indy. & $\begin{array}{c}\text { Descriptiva- } \\
\text { Indicativa }\end{array}$ \\
\hline Última Cruzada & $\begin{array}{l}\text { El cabecilla de los ladrones le regala su sombrero. Hay una elipsis hasta el momento actual donde Indiana } \\
\text { Jones está peleando con los sicarios del dueño de la Cruz. }\end{array}$ & Descriptiva \\
\hline Última Cruzada & En el campus, en una clase del Dr. Jones. & Descriptiva \\
\hline Última Cruzada & $\begin{array}{l}\text { El Dr. Jones logra entrar en su despacho traspasando un pasillo leno de estudiantes. Ya sentado en su } \\
\text { silla, tranquilo, toma una carta de Venecia-Italia. }\end{array}$ & Descriptiva \\
\hline Última Cruzada & Después de aceptar la oferta de Donovan para buscar el Grial, se despide de éste en el aeródromo. & Descriptiva \\
\hline Última Cruzada & $\begin{array}{l}\text { Búsqueda de la tumba del caballero en la biblioteca. Se esbozan unas notas que están en conflicto con el } \\
\text { resto de la música. }\end{array}$ & Descriptiva \\
\hline Última Cruzada & Indiana y su padre discuten ante unos solados nazis. Jones los ataca por sorpresa y se esboza su tema. & Descriptiva \\
\hline Última Cruzada & Indiana y su padre, logran soltarse y atacar a sala de descodificación. Suena unas notas del leitmotiv. & $\begin{array}{l}\text { Descriptiva- } \\
\text { Indicativa }\end{array}$ \\
\hline Última Cruzada & Perseguidos por los nazis vuelven a burlarlos, marchándose en moto. & Descriptiva \\
\hline Última Cruzada & Escapan por la estructura del dirigible. Ocupan la avioneta de emergencia. & Descriptiva \\
\hline Última Cruzada & Los jones vuelven a estar a salvo e Indiana está admirado por la acción de su padre en la playa. & Descriptiva \\
\hline Última Cruzada & Se enfrentan con Walter Donovan y sus aliados en las inmediaciones del lugar donde se encuentra el grial. & $\begin{array}{l}\text { Descriptiva - } \\
\text { Indicativa }\end{array}$ \\
\hline Última Cruzada & $\begin{array}{l}\text { El padre Jones salva a su hijo de caer por la grieta, suena el tema de Indiana Jones en tesitura grave y } \\
\text { despacio. }\end{array}$ & Descriptiva \\
\hline Última Cruzada & Padre e hijo discuten por el uso de "Junior" y marchan a galope. & Descriptiva \\
\hline
\end{tabular}

\section{Tabla 3: Secuencia de inserción y funciones del leitmotiv de Indiana Jones en 'La última cruzada'Fuente: Elaboración propia.}

\begin{tabular}{|c|c|c|}
\hline PELÍCULA & ACCIÓN & FUNCIÓN \\
\hline Calavera Cristal & $\begin{array}{l}\text { Tras salir dell maletero en el coche, Indiana se recompone, se pone su sobrero (lo vemos en silueta) y } \\
\text { suena el tema. Lento y piano, va cobrando intensidad. }\end{array}$ & $\begin{array}{l}\text { Descriptiva - } \\
\text { indicativa. }\end{array}$ \\
\hline Calavera Cristal & En la base militar, cuando los rusos le obligan a buscar el recipiente. & Descriptiva \\
\hline Calavera Cristal & En su enfrentamiento con los rusos logra escapar de la emboscada. & Descriptiva \\
\hline Calavera Cristal & Cuando estrella el coche contra el vehículo ruso. & Descriptiva \\
\hline Calavera Cristal & Indiana sale indemne de la detonacion del pueblo fantasma. & Descriptiva \\
\hline Calavera Cristal & Lo interrogan agentes del gobierno y lo ponen en duda la validez de Indiana. & Descriptiva \\
\hline Calavera Cristal & Hace su maleta en casa, tras saber que lo han expulsado de la Universidad. & Descriptiva \\
\hline Calavera Cristal & $\begin{array}{l}\text { En la estación, cuando va a coger un tren y dejar atrás su mundo, Indiana Jones mira hacia atrás con } \\
\text { melancolía. }\end{array}$ & Descriptiva \\
\hline Calavera Cristal & $\begin{array}{l}\text { Tras caer de la moto, Indiana vuelve a ganar el control. Y así, durante toda la pelea. Del mismo modo } \\
\text { cuando le dice a su alumno que salga de la biblioteca para hacer trabajo de campo. }\end{array}$ & $\begin{array}{l}\text { Descriptiva- } \\
\text { indicativa }\end{array}$ \\
\hline Calavera Cristal & Vuela hacia Perú & Descriptiva \\
\hline Calavera Cristal & $\begin{array}{l}\text { En el cementerio, después de la pelea con el asaltante. Están buscando la salida de la tumba subterránea } \\
\text { donde se metieron. Se oyen la primera frase del motivo. }\end{array}$ & $\begin{array}{l}\text { Descriptiva- } \\
\text { indicativa }\end{array}$ \\
\hline Calavera Cristal & Después de abrir la momia de uno de los descubridores españoles. Suena poco intensa y lenta. & Descriptiva \\
\hline Calavera Cristal & Encuentran la tumba de Orellana y se da cuenta que no hubo robo y siguen buscando. & Descriptiva \\
\hline Calavera Cristal & Los capturan los rusos y vuelan. A su paso por Amazonas vuelve a escucharse tema & Descriptiva- \\
\hline Calavera Cristal & Está descifrando lo que escribió Oxley. & Descriptiva \\
\hline Calavera Cristal & En el camión donde van atados, Mutt le pasa su navaja y se consigue liberar. & Descriptiva \\
\hline Calavera Cristal & Torpedea el campamento ruso. & Descriptiva \\
\hline Calavera Cristal & Escapan a través de lianas. & Descriptiva \\
\hline Calavera Cristal & Mutt quiere llevar el liderazgo, pero duda del camino. Entonces será Indiana quién asuma el mando,. & Descriptiva \\
\hline Calavera Cristal & Están saliendo del pozo. Se esboza tema de Indiana. & Descriptiva \\
\hline
\end{tabular}

\section{Tabla 4: Secuencia de inserción y funciones del leitmotiv de Indiana Jones en 'El reino de la} calavera de cristal' Fuente: Elaboración propia. 
En lo que se refiere a la función sustitutiva, no se ha encontrado este uso en el leitmotiv de Indiana Jones. Si bien en ocasiones en las películas se introduce el leitmotiv acompañando al sombrero de Jones, al látigo, al avión donde viaja o incluso- a la silueta del famoso arqueólogo no se puede hablar realmente de una sustitución del personaje mediante sus atributos, sino de una anticipación de su entrada en campo (música antecedente). Por ejemplo en El reino de la calavera de cristal, Indiana Jones recupera su mítico sombrero tras la lucha con el cargo ruso que es devorado por las termitas. El tema iniciado con el sombrero alcanza su máxima intensidad en el momento que ya luce en la cabeza de su dueño.

Además de la primera parte de Raiders March, el personaje de Indiana Jones se identifica con otro leitmotiv: el del joven Indy. Un leitmotiv que se utiliza únicamente en las primeras secuencias de La última cruzada, en un flashback a la primera aventura del famoso arqueólogo. Este tema cuenta con una melodía más sencilla y rítmica, instrumentos en tesituras más agudas y su ejecución es más rápida, porque identifica a un personaje joven, ágil y vivaz.

\begin{tabular}{|c|l|c|}
\hline PELÍCULA & \multicolumn{1}{|c|}{ ACCIóN } & FUNCIóN \\
\hline Última cruzada & Consigue escapar de la gruta donde estaban los ladrones. & Descriptiva \\
\hline Última cruzada & $\begin{array}{l}\text { Indy escapa a caballo y es perseguido por diversos vehículos. El tema se escuchará siempre que lleve } \\
\text { ventaja. }\end{array}$ & $\begin{array}{c}\text { Descriptiva - } \\
\text { indicativa }\end{array}$ \\
\hline Última cruzada & Consigue librarse del ladrón que lo tenía atrapado y prosigue su escapada. & Descriptiva \\
\hline Última cruzada & Los ladrones le ayudan a salir del vagón y se enfrentan a Indy. & Descriptiva \\
\hline Última cruzada & Indy sigue corriendo y llega a su casa deriva en el leitmotiv de Indiana Jones & Descriptiva \\
\hline
\end{tabular}

Tabla 5: Secuencia de inserción y funciones del leitmotiv de Indiana Jones joven. Fuente: Elaboración propia.

La utilización de este tema es fundamentalmente descriptiva subrayando momentos como el robo y escape de la gruta, la pelea en el tren y su llegada triunfante a casa. En algunos momentos este leitmotiv da paso al del Indiana adulto, subrayando las acciones que esbozan cualidades del arqueólogo.

Asimismo, en algunos de estas secuencias también se puede señalar una función indicativa en la misma línea que el leitmotiv de Indiana Jones. Durante la persecución, cuando Indy aventaja a los ladrones que lo persiguen su leitmotiv destaca respecto a la composición de fondo para desaparecer en aquellos momentos en los que lo vuelven a alcanzar.

\subsubsection{Temas musicales de las reliquias}

Al tratarse de una saga de aventuras cada película presenta un nuevo reto para el héroe. Este reto está vinculado a una reliquia de gran valor -el arca de la alianza, el santo grial, la cruz de Coronado- un objeto totémico de una tribu india -la piedra de Shankara- o unos restos mayas -la calavera de cristal. Su relevancia en la trama de las películas convierte a estos objetos en unos personajes más que, si bien no aparecerán en pantalla hasta prácticamente el final de la película, su presencia es 
constante desde que se plantea la aventura.

Cada uno de estos objetos está asociado a un tema musical que acompaña a los eventos clave en su consecución y promueve esta presencia constante. Incluso se puede determinar una función indicativa en la introducción de los temas: la escucha del tema adelanta el objeto de la aventura.

En la primera película En busca del arca perdida, este objeto es el arca de la alianza. Su leitmotiv -cuya composición sincopada, línea melódica e instrumentalización, con una base de violines y un efecto vibrato remite a lo misterioso y divino- se escucha desde la primera vez en que se hace referencia al arca durante una entrevista de Indiana Jones con dos agentes del Gobierno.

Indiana les muestra un grabado antiguo sobre el arca y el tema musical suena poderoso, produciéndose una identificación que se explotará a lo largo de la película así como en otras entregas de la saga.

\begin{tabular}{|l|l|l|}
\hline PELÍCULA & \multicolumn{1}{|c|}{ QUÉ SUCEDE } & FUNCIÓN \\
\hline Arca perdida & Indiana Jones enseña un grabado a los agentes del gobierno & Descriptiva-Indicativa \\
\hline Arca perdida & $\begin{array}{l}\text { Marcus informa a Indiana de que parte a buscar el arca. Tras hablar de } \\
\text { Marion, retoman la relevancia de la aventura. }\end{array}$ & Descriptiva \\
\hline Arca perdida & Marion muestra su medallón (cabezal del bastón) & Descriptiva-Indicativa \\
\hline Arca perdida & $\begin{array}{l}\text { Tras hablar con el anciano Sallah evita que Indiana Jones coma un dátil } \\
\text { envenenado. }\end{array}$ & Descriptiva \\
\hline Arca perdida & $\begin{array}{l}\text { En la cámara Indiana Jones descubre una inscripción que le permitirá } \\
\text { encontrar donde se encuentra el arca. }\end{array}$ & Descriptiva \\
\hline Arca perdida & Desata a Marion en la tienda, le dice que sabe donde está el arca & Descriptiva \\
\hline Arca perdida & Inspecciona la zona y ubica exactamente donde está el arca. & Descriptiva \\
\hline Arca perdida & Logran sacar el arca del pozo de almas. & Descriptiva \\
\hline Arca perdida & Transportan el Arca a través de un intrincado camino. & Descriptiva \\
\hline Arca perdida & $\begin{array}{l}\text { Abren el arca. El tema suena poderoso y trinunfal, orquestación } \\
\text { completa. }\end{array}$ & Descriptiva \\
\hline Arca perdida & $\begin{array}{l}\text { Ya en manos estadounidenses, llevan el arca para una zona secrera de } \\
\text { máxima seguridad. }\end{array}$ & Indicativa \\
\hline Última cruzada & En las catacumbas encuentran en una pared un grabado del arca. & Indicativa \\
\hline Calavera cristal & $\begin{array}{l}\text { En la base militar una caja se rompe y muestra brevemente su } \\
\text { contenido. }\end{array}$ & Indicativa \\
\hline
\end{tabular}

Tabla 6: Secuencia de inserción y funciones del leitmotiv del arca. Fuente: Elaboración propia.

Cada vez que Indiana da un paso más en su aventura para conseguir el arca, se puede escuchar el leitmotiv de este objeto: Marcus le informa de su partida, Marion muestra su medallón, descubre dónde se ubica el arca, logran sacar el arca del Pozo de almas, etc. En esta línea el leitmotiv también subraya algunas acciones de los nazis relacionadas con el arca, como el transporte o la apertura.

El leitmotiv del arca será retomado en La última cruzada, en el momento en el que Indiana y su acompañante encuentran en las catacumbas de la biblioteca un relieve en la pared, y en El reino de la calavera de cristal cuando, buscando el cuerpo del extraterrestre en el almacén de objetos clasificados, se cae y rompe una caja de 
madera. En ambos casos la introducción del leitmotiv tienen una función indicativa: señala la referencia (en el primer caso) y la presencia (en el segundo) del arca. Asimismo el empleo de este leitmotiv conecta estas películas con la primera en un guiño a los seguidores de la saga.

El arca es el único objeto cuya presencia se desarrolla a través de diversas películas de la tetralogía. Las restantes reliquias se limitan a la aparición de una película -al igual que su leitmotiv.

En El templo del mal, Indiana Jones asume el encargo de recuperar la piedra de Shankara. La primera vez que se escucha el leitmotiv de esta piedra es cuando se refieren a su existencia o, más concretamente a su falta. En este momento suena el tema, cuyo ritmo composición e instrumentalización recuerda a una marcha. Además de la piedra, el Maharahá ha desposeído al pueblo de niños, por lo que el empleo de este tema se hace extensible también a ellos.

La función del leitmotiv de la piedra de Shankará es fundamentalmente descriptiva, si bien su introducción con la llegada del niño huido al poblado y durante la interacción de Indiana con el niño-esclavo en la jaula remite a una función sustitutiva. Función que desaparece en las siguientes secuencias porque se ha producido una identificación de los niños del poblado con su piedra totémica.

Esta identificación se basa en que la piedra mágica y los niños del pueblo comparten un mismo destino. Ambos han sido robados, se utilizan para sacrificios en el templo, y son rescatados por Indiana Jones. En un momento en que Tapón es apresado por los Thuggee el leitmotiv de la piedra se entrelaza con el del personaje, ya que comparte suplicio con los niños del poblado

En La última cruzada, se presentan dos temas vinculados a reliquias históricas: la cruz de Cortés y el grial. La cruz se vincula exclusivamente a la primera parte de la película, concretamente a los dos momentos en los que este objeto histórico se cruza en la vida de Indiana Jones. El leitmotiv -de inspiración española para subrayar su origen- se utiliza siempre con una función descriptiva. Cuando acompaña a la aventura de Indiana Jones adulto se puede destacar también una función indicativa del tema: durante la pelea con los sicarios su inserción con variaciones señala en manos de quién está la cruz.

\begin{tabular}{|c|l|l|}
\hline \multicolumn{1}{|c|}{ PELÍCULA } & \multicolumn{1}{|c|}{ ACCIÓN } & FUNCIÓN \\
\hline Última cruzada & Los ladrones abren una caja. Suena la música mientras sacan la cruz. & Descriptiva \\
\hline Última cruzada & Indiana niño aprovecha un descuido de los ladrones para coger la cruz. & Descriptiva \\
\hline Última cruzada & $\begin{array}{l}\text { En el forcejeo encima del tren, a Indy se le cae la cruz en el vagón de } \\
\text { los rinocerontes. Se incluyen algunas notas en modo menor. }\end{array}$ & Descriptiva \\
\hline Última cruzada & Indy logra acorralar el león, ve la cruz y la coge. & Descriptiva \\
\hline Última cruzada & Entra en el despacho de su padre con la cruz en la mano & Descriptiva \\
\hline Última cruzada & Llega el Sheriff a su casa para pedirle la cruz. Conoce a su dueño. & Descriptiva \\
\hline Última cruzada & $\begin{array}{l}\text { El dueño de la cruz vuelve a tomarla del bolsillo de Indiana Jones, ya } \\
\text { adulto. Prosigue la pelea mientras la cruz pasa de unas manos a otras. }\end{array}$ & Descriptiva-indicativa \\
\hline
\end{tabular}

Tabla 7: Secuencia de inserción y funciones del leitmotiv de la cruz de Cortés.

Fuente: Elaboración propia. 
La cruz de Cortés se utiliza a modo de contextualización del personaje, sus atributos, sus valores y la relación con su padre. El grial, por su parte, constituye el objeto central de la aventura como se puede desprender del propio título.

Su leitmotiv se basa en una melodía de instrumentos de metal, de inspiración medieval, en textura media, con un tempo tranquilo -sobre una base más aguda, rápida y de menor intensidad- al tiempo que aporta cierta grandilocuencia a la escena.

La presentación del tema tiene lugar cuando Donovan muestra a Indiana Jones la inscripción que relata el paradero del grial. Dicha presentación, con el objeto ausente, similar a la del arca de la alianza, indicará al espectador que la búsqueda del grial va a constituir el cometido de la aventura.

A partir de esta primera introducción el tema sonará con una función descriptiva, en todos aquellos momentos en los que se produzca un avance o un suceso nuevo en relación con la búsqueda del grial: viaje, búsqueda de la tumba, encuentro con la hermandad de la espada cruciforme, conocimiento de la relevancia del grial, conflicto con los alemanes en las inmediaciones del lugar, la necesidad de la copa para salvar a su padre, acertijos o la curación de Henry Jones.

Además de en la presentación de la aventura se puede señalar una segunda inserción del leitmotiv, con una función indicativa al final de la película, cuando selecciona el grial entre las decenas de copas que están en la cámara. La confirmación de que se trata de la elección correcta se subraya con la inclusión del tema.

\begin{tabular}{|c|l|c|}
\hline PELÍCULA & \multicolumn{1}{|c|}{ ACCIÓN } & FUNCIóN \\
\hline Última cruzada & $\begin{array}{l}\text { En casa del Sr. Donovan quién le muestra una estela que señala el } \\
\text { lugar del Santo Grial. }\end{array}$ & Descriptiva-Indicativa \\
\hline Última cruzada & $\begin{array}{l}\text { En casa de su padre todo está devuelto. Abre la carta de Venecia-Italia } \\
\text { y descubre el diario de su padre. }\end{array}$ & Sustitutiva \\
\hline Última cruzada & En el avión, mientras consulta el diario del padre . & Descriptiva-Sustitutiva \\
\hline Última cruzada & En la búsqueda de la biblioteca. & Descriptiva \\
\hline Última cruzada & $\begin{array}{l}\text { En las catacumbas cuando encuentran y abren el sarcófago del } \\
\text { caballero cruzado. }\end{array}$ & Descriptiva \\
\hline Última cruzada & $\begin{array}{l}\text { Kazim le habla del secreto del grial y de la hermandad de la espada } \\
\text { cruciforme. También revela el paradero de su padre. }\end{array}$ & Descriptiva \\
\hline Última cruzada & $\begin{array}{l}\text { Después de enfrentarse a los nazis para salvar a Elsa Schneider, ésta } \\
\text { lo traiciona y le roba el diario del bolsillo. }\end{array}$ & Descriptiva \\
\hline Última cruzada & $\begin{array}{l}\text { El padre de Indiana le hace comprender la relevancia del grial para la } \\
\text { humanidad. }\end{array}$ & Descriptiva \\
\hline Última cruzada & $\begin{array}{l}\text { Tras recuperar el diario de su padre, en Berlín, vuelve a ponerse en } \\
\text { marcha en busca del grial. Padre e hijo cogen un zepelin. }\end{array}$ & Descriptiva \\
\hline Última cruzada & Walter vigila en la distancia el camino que toman. & Descriptiva \\
\hline Última cruzada & $\begin{array}{l}\text { Walter le dice que lo único que podrá salvar a su padre es el poder } \\
\text { curativo del grial. }\end{array}$ & Descriptiva \\
\hline Última cruzada & Indiana Jones prepara y pasa los acertijos para llegar al grial. & Indicativa \\
\hline Última cruzada & Indiana selecciona una copay bebe de ella para saber si es el grial. & Descriptiva \\
\hline Última cruzada & Indiana sana a su padre con el grial. & Sustitutiva \\
\hline Última cruzada & El padre de Jones ve al caballero cruzado que se despide & Descriptiva \\
\hline Última cruzada & Salen del espacio donde está el grial & \\
\hline
\end{tabular}

Tabla 8: Secuencia de inserción y funciones del leitmotiv del grial. Fuente: Elaboración propia. 
En este caso también se pueden señalar dos uso del leitmotiv con función sustitutiva. El diario de Henry Jones, en el que relata toda una vida buscando el cáliz, se acompaña de la música del grial hasta el punto de que se establece una unión entre ambos elementos repetida en varias ocasiones. Por otra parte, cuando Henry Jones se despide del caballero medieval, la escucha del tema implica una función sustitutiva: se está despidiendo del grial.

Finalmente en El reino de la calavera de cristal el objeto que motiva la búsqueda es precisamente la calavera de cristal. Este objeto está vinculado a un leitmotiv sencillo, de tres notas, que se repiten acompañadas de cierta disonancia, y que esbozan el carácter extraterrestre de la calavera.

\begin{tabular}{|c|l|c|}
\hline PELÍCULA & \multicolumn{1}{|c|}{ ACCIÓN } & FUNCIÓN \\
\hline Calavera cristal & $\begin{array}{l}\text { Encuentran el recipiente y dentro hay algo similar a una momia. Irina } \\
\text { rasga la cobertura ante la atónita mitada de todos. }\end{array}$ & Descriptiva-Indicativa \\
\hline Calavera cristal & Encuentra una calavera de cristal, pero no es la que buscan & Descriptiva \\
\hline Calavera cristal & Indiana se comunica con la calavera de cristal. & Descriptiva \\
\hline Calavera cristal & $\begin{array}{l}\text { Dentro de la cascada, en la cámara de los tesoros, Indiana toma la } \\
\text { calavera para colocarla en un grabado que le permite abrir una puerta. }\end{array}$ & Descriptiva \\
\hline Calavera cristal & Ya en su esqueleto la calavera sigue emitiendo sonido. & Descriptiva \\
\hline
\end{tabular}

Tabla 9: Secuencia de inserción y funciones del leitmotiv de la calavera de cristal. Fuente: Elaboración propia.

Es el tema con menor número de inserciones, todas ellas con una función descriptiva vinculada a la búsqueda y a la proximidad con el fin de la aventura.

Al igual que sucedía con el leitmotiv de Indiana Jones, la inserción de los temas vinculados a objetos no presentan siempre la misma forma, sino que varían de tempo, tonalidad, tesitura u orquestación en función de las necesidades narrativas de cada momento.

\subsubsection{Leitmotivs de amantes, amigos y familia}

Del mismo modo que sucede con las reliquias, también algunos de los personajes que desarrollan un papel relevante en la saga de Indiana Jones cuentan con un tema propio. Para el análisis de los leitmotivs de la saga se ha diferenciado entre aquellos personajes que tienen una relación de proximidad con Jones, que se va a reflejar en su colaboración con el héroe, y sus principales antagonistas.

Entre los leitmotivs de personajes próximos, resultan destacables las composiciones que acompañan a la trama amorosa de la saga y que se identificarán con las dos protagonistas de estos affaires. Marion y Willie.

Resulta representativo que la otra mujer con la que Indiana Jones establece una relación íntima, Elsa Schneider (La última cruzada), carezca de un acompañamiento musical específico. Una cuestión que, si bien puede resultar extraña en un principio, queda resuelta cuando asistimos a la traición de la arqueóloga. No es un affaire 
normal y así lo subraya la ausencia de música.

Marion protagoniza la primera trama amorosa en En busca del Arca Perdida, no obstante la introducción de este leitmotiv no se efectúa con su primera aparición en pantalla sino cuando su nombre es mencionado por Indiana en una conversación con Marcus. Esta introducción -similar a la del leitmotiv de los objetos- indica que Marion va a desarrollar un papel relevante en la aventura, una cuestión que se refrenda cuando el tema de la joven se entrelaza con el del arca en la misma conversación.

El leitmotiv de Marion constituye la segunda parte de Raiders march, una melodía que se desarrolla en tesitura media, con una orquestación sencilla -en comparación con el sinfonismo triunfal de la primera parte de la marcha- de timbre claro y un ritmo que redunda en el carácter íntimo y evocador del tema.

\begin{tabular}{|c|l|c|}
\hline PELÍCULA & \multicolumn{1}{|c|}{ ACCIÓN } & PUNCIÓN \\
\hline Arca perdida & $\begin{array}{l}\text { Cuando Indiana se prepara para marchase a buscar el arca, pregunta a } \\
\text { Marcus por Marion. Enlaza leitmotiv de arca. }\end{array}$ & Descriptiva-Indicativa \\
\hline Arca perdida & Viaje hacia El Cairo, deriva del leitmotiv de Indiana Jones. & Descriptiva \\
\hline Arca perdida & Marion decide quedarse al mono. & Descriptiva \\
\hline Arca perdida & $\begin{array}{l}\text { Indiana ve como el camión donde viaja Marion explota. La música se } \\
\text { hace más trágica. }\end{array}$ & Descriptiva \\
\hline Arca perdida & Indiana encuentra a Marion en la tienda y la besa. & Descriptiva \\
\hline Arca perdida & Marion se viste en la tienda con Belloq. Su leitmotiv se esboza. \\
\hline Arca perdida & Marion seduce a Indiana en el camarote. Él se queda dormido. & Descriptiva \\
\hline Arca perdida & $\begin{array}{l}\text { Se abrazan tras todo el periplo, una vez terminada la onda expansiva } \\
\text { provocada por el arca. El leitmotiv varía desde el arca. }\end{array}$ & Descriptiva-Indicativa \\
\hline Arca perdida & Indiana y Marion se encuentran en las escaleras. Lo invita a una copa. & Indicativa \\
\hline Calavera Cristal & Indiana se declara a Marion. & Descriptiva \\
\hline Calavera Cristal & Ella se une a Indiana cuando éste toma el control del coche. & Descriptiva \\
\hline Calavera Cristal & Cuando ya están todos a salvo, se esboza tema Marion. & Descriptiva-Indicativa \\
\hline Calavera Cristal & Marion e Indiana se casan. & Descriptiva \\
\hline
\end{tabular}

Tabla 10: Secuencia de inserción y funciones del leitmotiv de Marion. Fuente: Elaboración propia.

El empleo de esta composición se relaciona con una función descriptiva: suena en los momentos en los que se retoma la relación Indiana-Marion, pero también cuando ésta asume un pape activo como en la secuencia en la tienda de Belloq. El leitmotiv se esboza cuando Marion deja de asumir el papel de cautiva para intentar seducir al arqueólogo y conseguir su libertad.

La utilización de este tema, tras la apertura del arca, también puede responder a una función indicativa que señala que Jones y Marion están a salvo. Un empleo que resulta más patente al final de la película, cuando ambos personajes se encuentran en las escaleras. La invitación de Marion con el tema musical de fondo indica que la relación entre ambos personajes continúa.

En efecto, esta relación amorosa vuelve a tener presencia en la última película ( $E /$ reino de la calavera de cristal) y con ésta su leitmotiv. En esta película el empleo del tema de Marion es fundamentalmente descriptivo, añadiendo una función indicativa 
cuando después de la aventura de la calavera se encuentran finalmente a salvo. En este caso el leitmotiv ya no se asocia únicamente a Marion y a su relación con Indiana, sino que se amplía a Mutt convirtiéndose en un tema familiar (como se reflejará posteriormente en la boda).

En El templo maldito, la vedette Willie Scott se ve involucrada en la aventura de Indiana Jones convirtiéndose en la protagonista de la trama romántica de la película. La introducción de este tema tiene lugar durante la pelea del club, cuando la protagonista encuentra el antídoto que necesita Indiana y lo guarda. Este gesto, acompañado de un tema musical de tesitura aguda y ritmo ágil no sólo describe la situación sino que indica la relevancia de la joven en la nueva aventura de Jones.

\begin{tabular}{|c|l|c|}
\hline \multicolumn{1}{|c|}{ PELÍCULA } & \multicolumn{1}{|c|}{ ACCIÓN } & PUNCIÓN \\
\hline Templo maldito & En la pelea en el club Willie se hace cargo del antídoto para Indiana. & Descriptiva-Indicativa \\
\hline Templo maldito & En el avión, el tema de indiana da paso al tema de Willie. & Descriptiva \\
\hline Templo maldito & $\begin{array}{l}\text { Cuando caen por el precipicio en la balsa hasta el río. Seguirá sonando } \\
\text { en diversos momentos durante el accidentado viaje en el río. }\end{array}$ & Descriptiva \\
\hline Templo maldito & Dificultades para montar en el elefante. & Descriptiva \\
\hline Templo maldito & Willie echa perfume al elefante. & Descriptiva \\
\hline Templo maldito & Willi habla a Indiana de su abuelo, prestidigitador y pobre. & Descriptiva \\
\hline Templo maldito & $\begin{array}{l}\text { Indiana va a la habitación de Willie para llevarle comida. Despues de } \\
\text { diversas insinuaciones, se besan. }\end{array}$ & Descriptiva \\
\hline Templo maldito & $\begin{array}{l}\text { Willie entra en el pasadizo del palacio para ayudar a Indiana Jones. } \\
\text { Suenan unos compases de su tema. }\end{array}$ & Descriptiva \\
\hline Templo maldito & Indiana decide bajar a por las piedras de Shakara. Willie lo besa. & Descriptiva \\
\hline Templo maldito & Mientras Indiana Jones intenta rescatar a Willie. & Descriptiva \\
\hline Templo maldito & Indiana rescata a Willie, ella le da una bofetada para besarlo después. & Descriptiva \\
\hline Templo maldito & Willie se mete en la vagoneta. & Descriptiva-indicativa \\
\hline Templo maldito & Willie da un puñetazo a sus persecutores. Se esbozan su tema. & Descriptiva-indicativa \\
\hline Templo maldito & El hechicero se acerca a Willie y ella intenta lanzarlo al vacío. & Descriptiva-indicativa \\
\hline Templo maldito & $\begin{array}{l}\text { Hablan del destino de la piedra y del fin de las aventuras juntos. } \\
\text { Discuten. Se besan. }\end{array}$ & \\
\hline
\end{tabular}

Tabla 11: Secuencia de inserción y funciones del leitmotiv de Willie. Fuente: Elaboración propia.

Al igual que sucedía con el leitmotiv de Marion, el tema de Willie se utiliza fundamentalmente con una función descriptiva de la situación de la joven y de su relación con Indiana. Dicha composición subraya las vicisitudes de Willie en la aventura: la caída al río, sus problemas con el elefante, las dudas que tiene sobre la piedra, el reto que supone entrar en el pasadizo, etc. así como sus avances en la relación con Indiana: le habla de su abuelo, lo seduce en la habitación o el temor por su vida en el templo Thuggee.

Willie también asume un papel activo en la aventura. No sólo es víctima, sino que se defiende de sus agresores e incluso salva a Indiana. En estos momentos su leitmotiv se utiliza con una función descriptiva-indicativa ya que marca que su ventaja respecto a sus persectutores o su intento de acabar con el hechicero. Este uso, es similar al del leitmotiv de Indiana Jones.

En la secuencia final, la inclusión del tema de Willie subraya la continuidad de su 
complicada relación con Indiana (riñen-se besan-suena el leitmotiv). Este motivo musical da paso al de Tapón, destacando la relación a tres bandas que se establece en esta película, a la que se apela en diversos momentos del relato. Por ejemplo, cuando se ponen en marcha hacia el palacio de Pankot, la imagen presenta la relación de cada uno de los personajes con el elefante que los porta. Cada imagen estará asociada al leitmotiv de cada personaje.

Tapón es el niño amigo de Jones que le acompaña en su aventura en El templo maldito. Su papel en el relato va a quedar manifiesto desde su primera aparición, en la que el niño ayuda a escapar a Indiana del club mientras suena un tema musical muy ágil, en tesitura media, con un ritmo percutivo agudo con sonoridad oriental.

Este tema identificará al niño -en secuencias de montaje donde se presenta a los tres protagonistas de la aventura- su relación con Indiana Jones, así como aquellos momentos en los que Tapón desarrolla un papel activo. Un ejemplo de ello es el momento en que Tapón intenta ayudar a Jones en su pelea con el guerrero Thugee, o en su intervención para salvar a Willie. En ambos casos su tema destaca por encima de la composición disonante que acompañan a la acción.

\begin{tabular}{|c|l|c|}
\hline PELÍCULA & \multicolumn{1}{|c|}{ ACCIÓN } & FUNCIÓN \\
\hline Templo maldito & Caen en el coche que conduce Tapón. & Descriptiva \\
\hline Templo maldito & Tapón consigue darle esquinazo a sus persecutores. & Descriptiva \\
\hline Templo maldito & Tapón está preparado para marchar sobre lomo de un elefante. & Descriptiva \\
\hline Templo maldito & Van al palacio a buscar a los niños. El tema suena lento y expresivo. & Descriptiva \\
\hline Templo maldito & Capturan a Indiana, lo encarcelan con Tapón y Willie. Tapón lo abraza. & Descriptiva \\
\hline Templo maldito & Huída de Tapón de la mina, tras romper las cadenas. & Descriptiva-Indicativa \\
\hline Templo maldito & $\begin{array}{l}\text { Tapón corre entre los niños de la mina intetando escapar. Lo } \\
\text { persiguen. Se libra de su persecutor, ante la mirada atenta de los niños } \\
\text { y se vuelve a esbozar el tema de la piedra. }\end{array}$ & Descriptiva \\
\hline Templo maldito & Tapón trata de ayudar a Indiana en su pelea con la mole. & Descriptiva-Indicativa \\
\hline Templo maldito & $\begin{array}{l}\text { El Maharahá ataca a Indiana a través de un muñeco hechizado. Tapón } \\
\text { va a por él. }\end{array}$ & Descriptiva-Indicativa \\
\hline Templo maldito & $\begin{array}{l}\text { Los temas de Indiana y tapón se suceden, al igual que su participación } \\
\text { en la pelea. }\end{array}$ & Descriptiva \\
\hline Templo maldito & Una vez más el niño tiene que intervenir para salvar a Willie. & Descriptiva \\
\hline Templo maldito & $\begin{array}{l}\text { Cuando Indiana le riñe por perder el tiempo, Tapón lo saluda. El } \\
\text { Maharahá le dice como salir del palacio. }\end{array}$ & Descriptiva \\
\hline Templo maldito & Tapón está cruzando el puente. & . \\
\hline
\end{tabular}

Tabla 12: Secuencia de inserción y funciones del leitmotiv de Tapón. Fuente: Elaboración propia.

La función de este leitmotiv es fundamentalmente descriptiva, aunque se puede señalar un papel indicativo durante la persecución inicial o las peleas para marcar cuando Tapón lleva la iniciativa.

En La última cruzada Indiana Jones comparte aventura con su padre, quién contará con su propio tema musical. El leitmotiv de Henry Jones cuenta con una línea melódica clara en tesitura media-aguda, con un acompañamiento de metales, y una orquestación llena que dota de solemnidad a un personaje cuya experiencia vital se 
refleja en un ritmo más pausado que el de otros personajes.

\begin{tabular}{|c|l|c|}
\hline PELÍCULA & \multicolumn{1}{|c|}{ ACCIÓN } & PUNCIÓN \\
\hline Última Cruzada & $\begin{array}{l}\text { Llega Indiana al castillo donde está retenido en un castillo. Le cuenta } \\
\text { los avances que ha hecho en la investigación. }\end{array}$ & Descriptiva \\
\hline Última Cruzada & $\begin{array}{l}\text { Cuando Indiana y su padre son trasladados por los nazis hasta donde } \\
\text { está Walter Donovan. }\end{array}$ & Descriptiva \\
\hline Última Cruzada & $\begin{array}{l}\text { Henry Jones piensa que su hijo se ha caído por un precipicio y lamenta } \\
\text { su pérdida. Cuando vuelve a aparecer y se abrazan suena su tema. }\end{array}$ & Descriptiva-indicativa \\
\hline Última Cruzada & $\begin{array}{l}\text { Walter vuelve a capturar a Jones en el lugar donde se encuentra el } \\
\text { grial. Tras una discusión dispara a Henry Jones. }\end{array}$ & Descriptiva \\
\hline Última Cruzada & Se encuentra con el caballero cruzado que está guardando el grial. & Descriptiva \\
\hline Calavera Cristal & $\begin{array}{l}\text { Indiana se lamenta de las pérdidas personales que ha vivido en los } \\
\text { últimos años. Sobre la mesa hay una foto de su padre. }\end{array}$ & Indicativa \\
\hline
\end{tabular}

Tabla 13: Secuencia de inserción y funciones del leitmotiv de Henry Jones.

Fuente: Elaboración propia.

El tema de Henry Jones se utiliza fundamentalmente con una función descriptiva de la relación con su hijo, de los momentos en los que ambos se enfrentan a Walter Donovan y sus aliados nazis, o de su relación con el grial (como cuando se percata de la existencia del caballero cruzado).

Además de la función descriptiva se puede señalar un uso indicativo del tema mientras Henry Jones se lamenta en el borde del precipicio donde cree que murió su hijo. Cuando aparece Indiana la inclusión del tema, lento y melancólico indica que se retoma esta relación entre padre e hijo.

El tema de Henry Jones volverá a utilizarse con una función indicativa en El reino de la calavera de cristal cuando Indiana habla con el rector de la Universidad de su vida y de las pérdidas sufridas en los últimos años. Al mencionar dichas pérdidas suena el tema de su padre indicando que éste -presente en una foto - ha fallecido.

En esta película, la última de la saga, Indiana Jones comparte su aventura con un joven greassy llamado Mutt. Este joven desarrolla un papel relevante en la película como muestra su identificación con un tema propio. El tema de Mutt se caracteriza por una melodía ágil, tesitura media-aguda y orquestación llena aunque con protagonismo de la familia de viento madera, que refleja la juventud del personaje y su interés por la aventura.

\begin{tabular}{|c|l|c|}
\hline PELÍCULA & \multicolumn{1}{|c|}{ ACCIÓN } & FUNCIÓN \\
\hline Calavera cristal & Indiana y Mutt escapan de la cafetería perseguidos por los rusos. & Descriptiva \\
\hline Calavera cristal & $\begin{array}{l}\text { En el avión hacia Perú. Mutt está comprobando el estado de su moto. El } \\
\text { leitmotiv de Indiana da paso al de Mutt y éste otra vez el de indiana. }\end{array}$ & Descriptiva \\
\hline Calavera cristal & Buscando una tumba en el cementerio. & Descriptiva \\
\hline Calavera cristal & $\begin{array}{l}\text { Marion e Indiana están metidos hasta el fondo en arenas movedizas. } \\
\text { Ella le dice que Mutt es su hijo. }\end{array}$ & Sustitutiva \\
\hline Calavera cristal & Comienza un duelo de espadas con Irina. Indica quién está ganando. & Descriptiva-Indicativa \\
\hline
\end{tabular}

Tabla 14: Secuencia de inserción y funciones del leitmotiv de Mutt. 
Fuente: Elaboración propia.

Su empleo es fundamentalmente descriptivo, habitualmente relacionado con su interacción con Indiana Jones. En las peleas también asume una función indicativa, que señala cuando Mutt domina la contienda, como en el caso de otros personajes. Más allá de este empleo, similar al de los otros temas musicales, el leitmotiv de Mutt se va a utilizar con una función sustitutiva. Engullidos por las arenas movedizas Marion le confiesa a Indiana la identidad del joven mientras Mutt se hace presente en la conversación a través de su tema.

El tema del joven sonará en una secuencia más, la lucha de espadas con Irina, para después desaparecer a favor del leitmotiv de Marion -que pasa a identificar la familia- o de Indiana Jones cuando en la secuencia final el sombrero cae en los pies de Mutt (Henry Jones III) señalando una posible continuidad de la saga familiar.

\subsubsection{Temas musicales de enemigos}

Las aventuras de Indiana Jones no serían lo mismo si, en su búsqueda del objeto histórico, no tuviese que enfrentarse a una serie de personajes opositores y enemigos.

Aunque en la primera entrega de la saga estos enemigos carecen de un tema propio identificándose con temas de ritmo percutivo -que recuerdan a marchas militares-, composiciones disonantes -que subrayan el desarrollo de la acción- o motivos de inspiración árabe -que marcan el color local de la música-, a partir de El templo maldito se dotará a los contrincantes de un leitmotiv.

Esta película [El templo maldito], los Thuggee cuentan tema propio, ejecutado por instrumentos de viento metal y en modo menor que -junto a los tambores y los coros que acompañan al sacrificio- constituirá la música identificativa del templo subterráneo. Los Thugge solamente tienen entidad en la sala sacrificial y en la mina, por lo que el leitmotiv se asocia exclusivamente a estos espacios.

En La última cruzada, aunque el enemigo tiene muchas caras -Donovan, Schneider, la Gestapo y los mandos del ejército nazi- todas ellas van a identificarse con un único tema musical. Este tema es una composición con un fraseo rítmico -que recuerda una marcha- orquestación llena que le dota de solemnidad, pero modo menor que refleja la esencia real de estos personajes. 


\begin{tabular}{|c|l|c|}
\hline PELÍCULA & \multicolumn{1}{|c|}{ ACCIÓN } & PUNCIÓN \\
\hline Última cruzada & $\begin{array}{l}\text { En el salón del palacio, a donde han conducido a los Jones, Walter se } \\
\text { presentará como antagonista. }\end{array}$ & Descriptiva -Indicativa \\
\hline Última cruzada & Marcus es atrapado en Egipto. & Indicativa \\
\hline Última cruzada & $\begin{array}{l}\text { Elsa y Donovan salen del lugar donde están retenidos los Jones, cada } \\
\text { uno de ellos con un destino diferente. }\end{array}$ & Descriptiva \\
\hline Última cruzada & $\begin{array}{l}\text { En cuanto los nazis comienzan a darle alcance, se esboza su leitmotiv } \\
\text { en la música de acción. }\end{array}$ & Descriptiva -Indicativa \\
\hline Última cruzada & $\begin{array}{l}\text { Ya en el aire, cuando los Jones se preparan para continuar su aventura, } \\
\text { se dan cuenta de un cambio de rumbo del dirigible. }\end{array}$ & Descriptiva \\
\hline Última cruzada & $\begin{array}{l}\text { Los nazis avanzan por el desierto equipados por tanques para } \\
\text { encontrar el punto exacto donde se esconde el grial. }\end{array}$ & Descriptiva \\
\hline Última cruzada & $\begin{array}{l}\text { Henry Jones va a rescatar a su amigo Marcus al tanque nazi y es } \\
\text { sorprendido. }\end{array}$ \\
\hline Última cruzada & $\begin{array}{l}\text { Después de la persecución de Indiana con los tanques. Sale por la } \\
\text { escotilla el coronel nazi y se encuentran frente a frente. }\end{array}$ & Descriptiva- Indicativa \\
\hline Última cruzada & $\begin{array}{l}\text { A lo largo de la pelea para llegar primeros al lugar donde se ubica el } \\
\text { grial, suena varias veces. }\end{array}$ & Descriptiva -Indicativa \\
\hline
\end{tabular}

Tabla 15: Secuencia de inserción y funciones del leitmotiv de los Nazis.

Fuente: Elaboración propia.

Este leitmotiv se introduce por primera vez cuando Indiana y Henry Jones, capturados por los nazis y despojados del diario, son trasladados al salón del castillo. Aquí les espera Donovan por lo que el tema musical queda asociado - a través de una función indicativa- a las tres caras del enemigo: Walter Donovan, Elsa Shneider y los mandos nazis.

La identificación de este tema con los nazis indicará al espectador quiénes son los responsables del rapto de Marcus en Egipto dado que, durante la interacción del Rector con sus captores, se vuelve a escuchar el tema.

Al igual que sucede con otros leitmotivs, el uso de esta composición suele estar asociado a una función descriptiva que subraya aquellos momentos en los que los nazis (y sus aliados) van un paso por delante de los Jones o los sorprenden. A este uso del leitmotiv también se puede añadir una función indicativa, para señalar su domino en aquellos momentos de persecución y contienda.

También Irina, quién personifica al amigo ruso en El reino de la calavera de cristal cuenta con su propio tema identificativo. Una composición en tesitura media-grave, con una tonalidad menor y una orquestación sencilla, que acompañará a la agente del KGB a lo largo del film.

La primera vez que aparece Irina, en la base americana tomada por los rusos, se introduce su tema musical que ayudaa completar la descripción del personaje al tiempo que lo señala (función indicativa) como antagonista principal de su aventura. 


\begin{tabular}{|c|l|c|}
\hline PELÍCULA & \multicolumn{1}{|c|}{ ACCIÓN } & PUNCIÓN \\
\hline Calavera cristal & $\begin{array}{l}\text { Se presenta en la base tomada por los rusos, cuando están a punto de } \\
\text { tomar medidas con Indiana Jones y los frena. }\end{array}$ & Descriptiva-Indicativa \\
\hline Calavera cristal & Irinar vuelve a tomar el mando de sus hombres. & Descriptiva \\
\hline Calavera cristal & $\begin{array}{l}\text { Cuando está en el interrogatorio con los agentes del Gobierno, y le } \\
\text { habla de Irina éstos le presentan su historial }\end{array}$ & Descriptiva \\
\hline Calavera cristal & $\begin{array}{l}\text { Irina le cuenta a Indiana su teoría de que la calavera pertenece a seres } \\
\text { de otro planeta. }\end{array}$ & Descriptiva \\
\hline Calavera cristal & Se encuentra con Irina que agarra la calavera & Descriptiva \\
\hline Calavera cristal & Se queda sin armas y decide usar la espada. & Descriptiva \\
\hline Calavera cristal & Indiana y su familia marchan ante la atenta mirada de Irina. & Descriptiva \\
\hline Calavera cristal & Irina encuentra el rastro de Indiana y lo sigue & Indicativa \\
\hline Calavera cristal & $\begin{array}{l}\text { Irina le pide tener todo el conocimiento a la calavera .Se esboza su } \\
\text { tema excesivamente agudo y rápido. }\end{array}$ & Descriptiva \\
\hline Calavera cristal & A Irina le están cargando tanta información que le explotan los ojos. & \\
\hline
\end{tabular}

Tabla 16: Secuencia de inserción y funciones del leitmotiv de Irina.

Fuente: Elaboración propia.

El uso de este tema es fundamentalmente descriptivo: situación de Irina, su relación con Indiana y -por extensión- de los avances efectuados por los rusos (el nuevo enemigo de América en la Guerra Fría).

Sin embargo su empleo, en el momento en que Irina pide a los extraterrestres tener todo el conocimiento del mundo, responde a una función indicativa. El tema suena chirriante, en una tesitura excesivamente aguda y acelerado, lo que resulta premonitorio del final de la agente. Poco después su tema vuelve a sonar -ahora con una función descriptiva- mientras asistimos a la desintegración de su cerebro.

\section{CONCLUSIONES}

El análisis de la tetralogía de Indiana Jones ha permitido destacar un empleo profuso del leitmotiv. Estos temas acompañan a diversos actantes de las películas: protagonista (también en su versión juvenil), sus relaciones amorosas, amigos, enemigos e incluso reliquias y objetos mágicos que motivan sus aventuras.

El uso del leitmotiv constituye un elemento característico de la saga en sus diversas entregas. Si bien en la primera película la banda sonora introduce tres temas recurrentes vinculados a Indiana Jones, Marion y el arca, su empleo se ampliará en los siguientes films a otros personajes y objetos.

El leitmotiv de Indiana Jones supone un atributo más en la caracterización del personaje -al igual que su látigo y sombrero- hasta el punto de constituir la marca sonora de toda la saga. Del mismo modo, este tema no significaría nada sin el personaje de Lucas.

Esta interrelación plantea -siguiendo a Winters (2010)- una cuestión problemática en lo que respecta al estudio de la música fílmica. El tema de Indiana Jones se puede catalogar como música extradiegética en tanto que la fuente de esta música no sólo se encuentra ausente de la imagen sino que es externa a la acción -pertenece al 
mundo de los fosos imaginarios- por lo que podría ser sustituida por cualquier otra. Pero realmente ¿sería lo mismo seguir las aventuras de Indiana Jones con otro acompañamiento que no fuesen los primeros compases de The raiders march?

La reiteración de la primera parte de Raiders March en todas las películas de la tetralogía y la recuperación de algunos leitmotivs que fueron relevantes en los films precedentes (el arca, el tema de Marion o de Henry Jones padre) dotan a la saga de unidad y coherencia, al tiempo que permiten incrementar el engagement del espectador con el universo Indiana Jones.

Respecto a las funciones narrativas de los leitmotivs, se puede destacar el predominio del uso descriptivo. Una función que se refleja en las diversas variaciones del mismo tema musical introdiucidos durante los momentos de acción vinculados a un determinado personaje o relacionados con un determinado objeto.

Dichas variaciones (orquestación, tesitura, tonalidad, tempo) que en ocasiones se esbozan sobre otra composición musical, permiten describir el momento en el que se encuentra el actante al que caracterizan e incluso la acción.

Cuando se desencadena un conflicto el leitmotiv sonará sobre una base compositiva cargada de disonancias, mientras que si está próximo a resolverse ambas músicas (leitmotiv + score) irán volviéndose cada vez más consonantes. Este empleo confirma el código armónico señalado por Frith (1998) para las secuencias de acción.

Asimismo en las secuencias de acción, persecución o conflicto se puede señalar una función indicativa del leitmotiv dado que además de describir la situación, suele destacar quién lleva la ventaja en cada momento. Esta función indicativa también se presenta en la introducción -por vez primera- del tema de cada objeto histórico o de determinados personajes en tanto que señalan cuál es elemento central de la aventura, quién tendrá una relación cercana con el protagonista o quién se convertirá en al antagonista.

En definitiva, el empleo del leitmotiv en la saga de Indiana Jones dota de una nueva dimensión a la narración fílmica con la inclusión y reiteración de dichos temas identificativos. La composición, variaciones y funciones de los leitmotivs conforman un código audiovisivo que enriquece la experiencia del espectador y lo sumerge en el universo del mítico aventurero.

\section{REFERENCIAS}

\section{LIBROS, CAPÍTULOS DE LIBRO O ENTRADA DE UN LIBRO DE CONSULTA, INFORMES TÉCNICOS, TESIS}

Adorno, T. y Eichler, H. (1981). El cine y la música. Madrid: Fundamentos.

Aumont, J. y Michel, M. (1990). Michel Análisis del film. Barcelona: Paidós Comunicación. 
Aschieri, R.: (1999). Over the Moon, La música de John Williams para el cine. Chile: Universidad Diego Portales Press.

Beltrán Moner, R. (1991). Ambientación musical. Madrid: Instituto Oficial de la Radio Televisión Española.

Burt, G. (1994). The art of film music. Boston: Northearstern University Press.

Caldevilla Domínguez, D. (2005). El sello de Spielberg. Madrid: Vision Net.

Caldevilla, D. (2000). El estilema de autor en Steven Spielberg: Un sello personal en lo audiovisiual (Tesis de doctorado), Universidad Complutense de Madrid, Madrid.

Champlin, C. (1992). George Lucas. The Creative Impulse. New York: H.N. Abrams.

Chion, M. (1993). La Audiovisión. Introducción a un análisis conjunto de la imagen y el sonido. Barcelona: Paidós.

Chion, M. (1997). La música en el cine. Barcelona: Paidós.

Frith, S. (1988). Music for pleasure: essays on the Sociology of Pop. Cambridge, Cambridge University Press.

Gorbman, C. (1987). Unheard Melodies. Londres: The British Film Institute.

Jullier, L.(2007). El sonido en el cine. Barcelona: Paidós.

López Olano, C. (2001). En busca del arca perdida. Barcelona Octaedro.

Schaeffer, P. (1966). Traité des objets musicaux. Paris: Le Seuil.

Scheurer, T. E. (1997) John Williams and film music since 1971, en Popular Music and Society, 21 (1), 59-72, DOI: 10.1080/03007769708591655

Torelló, J. y Duran, J. (2014). Michel Chion en La audiovisión y una propuesta práctica sobre un fragmento de Nostalgia de Andrei Tarkovski, en L'Atalante, 18, 111-117.

\section{PUBLICACIONES PERIÓDICAS, REVISTAS, WEBES Y SIMILARES:}

Bezuidenhout, F. J. T. (2009). Music as brand, with reference to the film music of 
John Towner Williams (with particular emphasis on williams's'main title' for star wars), (Tesis de Master), University of the Witwatersrand. Johanesburgo. Recuperado de http://wiredspace.wits.ac.za/jspui/handle/10539/7041?mode=full Consultado el 14/12/2014.

Costantini (2001). No con un estallido sino con un gemido: fuentes literarias del diseño de sonido en Apocalypse Now Filmsound. Recuperado de http://filmsound.org/gustavo/apocalypsenow.htmConsultado el 14/12/2014.

Costantini, G. (2002). Leitmotif Revisited, en Filmsound. Recuperado de http://filmsound.org/gustavo/leitmotif-revisted.htm. Consultado el 14/12/2014.

Gertrúdix Barrio, M. y García García, F. (2013). El discurso musical en el cine: el proceso de composición musical desde el análisis de sus estrategias narrativas, enGómez Martínez, A. (Coord.) Nuevos discursos y constitución del punto de vista. Madrid: Icono 14. Recuperado de http://apolo.uji.es/fjgt/Teorias\%20extracto.pdf. Consultado el 14/12/2014.

Lincoln, D.A. (2011). The art and craft of John Williams (Tesis de posgrado), Oregon State Universtity, Oregon. Recuperado de

https://ir.library.oregonstate.edu/xmlui/bitstream/handle/1957/22075/Final\%20Thesi s\%20-\%20Danae\%20Lincoln.pdf?sequence=1. Consultado el 17/12/2014.

Peña, B. (2009). La emoción en el cine, en Vivat Academia, 102. Recuperada de http://www2.uah.es/vivatacademia/numeros/n102/investig.htm Consultado el $17 / 12 / 2014$.

Reginfo Gómez, J.P. (2010). Imagen, publico y sonido. Relaciones entre el séptimo arte y música, en Astrolabio, 9 (1), Recuperado de http://www.revistaelastrolabio.com/ediciones-anteriores/volumen_9-

1/astrolabio_vol9_1_art8 Consultado el 17/12/2014. 